\title{
Visual outcome after phacoemulsification and IOL implantation in diabetic patients
}

\author{
Anna Zaczek, Göran Olivestedt, Charlotta Zetterström
}

\begin{abstract}
Aims-To follow visual acuity (VA) and progression of diabetic retinopathy (DR) after phacoemulsification in diabetic patients with different stages of DR and controls.

Methods-This prospective study included 27 diabetic patients with no or mild to moderate non-proliferative DR; 25 patients with moderate to severe nonproliferative, or proliferative DR; and 22 non-diabetic controls. All patients underwent uncomplicated, phacoemulsification surgery, with implantation of a heparinsurface modified (HSM) poly(methylmethacrylate) (PMMA) intraocular lens (IOL) into the capsular bag. Colour fundus photographs and fluorescein angiograms (FA) were taken at 1 week (baseline), 3 months, and 1 year postoperatively to determine stability or progression of DR.
\end{abstract}

Results-The VA of 46 diabetic eyes (88\%), was improved 1 year after surgery and only six eyes $(12 \%)$ were unchanged or worse. 41 diabetic eyes $(79 \%)$ achieved a VA of 0.5 or better and 11 eyes $(21 \%)$ had a final VA lower than 0.5 . Significantly lower final corrected VA was found 1 year after surgery in eyes with advanced DR (median 0.5 ; range $0.1-1.0$ ) compared with controls $(1.0 ; 0.1-1.0)$ and eyes with no or mild to moderate DR (1.0; 0.1-1.0). Eyes with mild to moderate DR and clinically significant macular oedema (CSMO) 1 week postoperatively had a lower final VA than those without CSMO. Angiographic cystoid macular oedema (CMO) was detected with FA in $15 \%$ of all diabetic eyes 1 week postoperatively. 41 eyes (79\%) showed no change or improvement of the retinal status 1 year after cataract surgery. Progression was found in 11 eyes $(21 \%)$, mainly in eyes with mild to moderate DR and moderate to severe DR. Eyes with an indication for laser photocoagulation at baseline showed a significantly higher rate of progression of DR after surgery than those without indication for laser treatment.

Conclusion-The final visual outcome was improved in the majority of diabetic eyes. Eyes with CSMO at the time of surgery had the worst prognosis regarding postoperative VA.

(Br F Ophthalmol 1999;83:1036-1041)

Dr Anna Zaczek, St Erik's

Eye Hospital, Polhemsgatan

50, S-112 82, Stockholm,

Sweden.

Accepted for publication 21 May 1999

Patients with diabetes mellitus (DM) have a higher prevalence of lens opacities ${ }^{1}$ and de- velop cataract at an earlier age than non-diabetics. ${ }^{2}$ Cataract in diabetic patients decreases the visual acuity, makes an adequate examination of the retina harder or impossible, and photocoagulation of diabetic retinopathy more difficult. Therefore, it is important to perform cataract surgery for visual rehabilitation and for diagnostic and therapeutic reasons, even if there is a potential risk of aggravating the retinopathy.

Progress in surgical technique from intracapsular cataract extraction to extracapsular cataract extraction (ECCE) and improvements in intraocular lens (IOL) technology have increased the indications for cataract surgery in diabetic patients. However, ECCE requires a large incision and the nucleus is expressed through the pupil with a certain degree of iris trauma. Phacoemulsification technique allows the surgeon to remove a cataract through a smaller incision than with manual ECCE. Phacoemulsification also has an advantage over previous cataract surgical procedures because of quick recovery of vision ${ }^{3}$ and less postoperative inflammation. ${ }^{4}$ Heparin coated IOLs, may also be suitable for diabetic eyes because of decreased postoperative inflammation. ${ }^{56}$

The purpose of this prospective study was to investigate the effect of phacoemulsification cataract surgery, with heparin-surface modified (HSM) IOL implantation, on the visual acuity in diabetic patients with cataract and with different stages of diabetic retinopathy, and to evaluate prospectively the changes in diabetic retinopathy following cataract surgery.

Materials and methods

PATIENTS

This study included 55 consecutive patients with $\mathrm{DM}$ and 22 controls, who underwent uncomplicated, standardised phacoemulsification surgery, with implantation of an HSM IOL into the capsular bag at St Erik's Eye Hospital, Stockholm (Table 1). The diabetic patients were referred from the diabetes outpatient clinic at the hospital and ophthalmologists in the Stockholm area. Eyes with glaucoma, uveitis, age related macular degeneration, a history of trauma, or any previous ocular surgical procedures were excluded. During the study, one patient died and two patients were lost to follow up; so, the number of patients with DM who finished the study was 52 . For each diabetic patient a standardised medical protocol was done with information of the type and duration of diabetes, sex and age, and any diabetic medications.

Control patients were also selected from 
Table 1 Clinical characteristics of patients with diabetes mellitus and controls operated on for cataract

\begin{tabular}{|c|c|c|c|}
\hline & \multirow[b]{3}{*}{ Control } & \multicolumn{2}{|l|}{ Diabetes } \\
\hline & & \multicolumn{2}{|c|}{ Diabetic retinopathy } \\
\hline & & No/mild-moderate & Moderate-severe/proliferative \\
\hline Number of eyes & 22 & $\begin{array}{l}27 \\
(9 / 18)\end{array}$ & $\begin{array}{l}25 \\
(12 / 13)\end{array}$ \\
\hline \multicolumn{4}{|l|}{ Age at surgery (years) } \\
\hline Median & $\begin{array}{l}76 \\
(48-88)\end{array}$ & $\begin{array}{l}73 \\
(49-86)\end{array}$ & $\begin{array}{l}73 \\
(53-83)\end{array}$ \\
\hline \multicolumn{4}{|l|}{ Sex } \\
\hline Male & 12 & 11 & 9 \\
\hline Female & 10 & 16 & 16 \\
\hline \multicolumn{4}{|l|}{ Duration of diabetes (years) } \\
\hline Median & - & 15 & 20 \\
\hline Range & - & $(5-50)$ & $(8-55)$ \\
\hline \multicolumn{4}{|l|}{ Treatment } \\
\hline Insulin or insulin + tablets & - & 18 & 19 \\
\hline Tablets alone & - & 6 & 6 \\
\hline Diet & - & 3 & - \\
\hline \multicolumn{4}{|l|}{ Diabetes } \\
\hline Type 1 & - & 2 & 4 \\
\hline Type 2 & - & 25 & 21 \\
\hline CSMO at baseline & - & 5 & 12 \\
\hline Preoperative laser treatment & - & 6 & 17 \\
\hline Indication for laser treatment at baseline & - & 9 & 22 \\
\hline \multicolumn{4}{|l|}{ Postoperative laser treatment: } \\
\hline none & - & 15 & 3 \\
\hline focal or grid & - & 11 & 4 \\
\hline scatter or scatter with grid & - & 1 & 18 \\
\hline Postoperative Nd:YAG capsulotomy & - & - & 1 \\
\hline
\end{tabular}

CSMO = clinically significant macular oedema; baseline $=1$ week after surgery.

ria were used as in diabetic patients. A routine ophthalmological examination was performed preoperatively and 1 day, 1 week, 3 months, and 1 year after surgery in all patients. It included the best corrected visual acuity, applanation tonometry, biomicroscopy, and fundal examination by direct and indirect ophthalmoscopy. Uncorrected and best corrected visual acuity was measured using the Snellen 5 metre chart.

SURGERY

A phacoemulsification surgical procedure was performed by one surgeon $(\mathrm{CZ})$ in one eye of each patient who were enrolled in the study. After a superior $3.2 \mathrm{~mm}$ scleral pocket incision, anterior continuous capsulorhexis, and hydrodissection the nucleus was removed with a cracking technique. After extending the incision $3.2 \mathrm{~mm}$ to $5.2 \mathrm{~mm}$, an HSM poly (methylmethacrylate) (PMMA) IOL (PharmaciaUpjohn, type 809 C), with an optic diameter of $5.0 \mathrm{~mm}$, was implanted into the capsular bag with the aid of sodium hyaluronate (Healon). The wounds were not sutured. No complications were recorded. The eyes were treated postoperatively with $0.1 \%$ dexamethasone (Isopto-Maxidex, Alcon) three times a day for 1 week, twice daily for the second week, and once daily during the third week. Three diabetic patients received dexamethasone five times a day during the first postoperative week because of more pronounced postoperative inflammation. Non-steroidal antiinflammatory eye drops $0.1 \%$ diclofenac (Voltaren Ophtha, Ciba Vision) were used in two diabetic patients with clinically significant macular oedema (CSMO). One control patient received additional treatment with dexamethasone and diclofenac at 3 months after surgery, because of cystoid macular oedema (CMO).
Laser photocoagulation was performed in diabetic eyes according to the indications defined by the Early Treatment Diabetic Retinopathy Study (ETDRS). ${ }^{7}$ Laser treatment consisted of panretinal photocoagulation (scatter) for proliferative and severe nonproliferative diabetic retinopathy. Focal or grid argon laser photocoagulation was performed for CSMO or according to fluorescein angiography (FA) photographs. Some of the patients had previously undergone laser photocoagulation treatment, but not during the 4 months before surgery (Table 1). Postoperative laser treatment was performed no sooner than 2 weeks after the operation (Table 1).

\section{DIABETIC RETINOPATHY STATUS AND FUNDUS} PHOTOGRAPHY

Diabetic retinopathy (DR) was documented with a Canon (CF-60 UV) fundus camera. Seven colour fundus photographs with stereo pairs of the macula and fluorescein angiograms were taken after pharmacological mydriasis at 1 week (baseline), 3 months, and 1 year postoperatively in patients with diabetes mellitus. All colour photographs and fluorescein angiograms were graded by a retinal specialist (GO) in a masked fashion concerning both patients and time. In most cases, the preoperative level of DR was difficult to estimate because of dense cataract. Therefore, the baseline stage of DR was estimated according to the photographic examinations performed at the outpatient visit 1 week after surgery.

Levels of DR were defined according to the Wisconsin Epidemiologic Study of Diabetic Retinopathy Classification. ${ }^{8}$ Levels of retinopathy were then divided into four groups: no DR (level 10), mild to moderate DR (levels 21, $31)$, moderate to severe DR $(41,51)$, and proliferative DR (levels 60, 61, 65, 80). Clinically significant macular oedema (CSMO) was classified according to the Early Treatment Diabetic Retinopathy Study Research Group. ${ }^{7}$ The diagnosis of angiographic cystoid macular oedema (CMO) was based on fluorescein angiography, which revealed the typical appearance of $\mathrm{CMO}$ as described by Gass and Norton. ${ }^{9}$

Based on colour fundus photographs and fluorescein angiograms performed at 1 week, 3 months, and 1 year after surgery, the diabetic retinal findings were classified into three groups. The first group was defined as "no change", where no aggravation of DR was found. The second group, defined as "better", consisted of eyes wherein DR improved within the stage or reduced to a lower level of DR. The third group consisted of eyes with progression of DR. Progression was considered to have occurred after surgery when (1) a patient with no pre-existing DR developed non-proliferative DR or proliferative $\mathrm{DR}$, with or without progression within the macula; (2) a patient with pre-existing DR showed aggravation of changes, with or without progression within the macula; (3) a patient with PDR showed postoperative recurrence of proliferative or other changes, with or without progression within the macula. Stability or changes in 
Table 2 Best corrected visual acuity (VA) in diabetic patients with different stages of diabetic retinopathy (DR) and controls, before and after surgery. All values of VA are given as median (range)

\begin{tabular}{|c|c|c|c|c|}
\hline \multirow[b]{3}{*}{ Group } & \multicolumn{4}{|l|}{ Visual acuity ${ }^{*}$} \\
\hline & \multirow[b]{2}{*}{ Preoperative } & \multicolumn{3}{|l|}{ Postoperative } \\
\hline & & 1 week & 3 months & 1 year \\
\hline Control & $0.4(0.01-0.8)$ & $10(0.8-1.0)$ & $1.0(0.5-1.0)$ & $1.0(0.5-1.0)$ \\
\hline No DR or mild-moderate DR & $0.3(0.13-0.65)$ & $0.8(0.3-1.0)$ & $1.0(0.3-1.0)$ & $1.0(0.1-1.0)$ \\
\hline Advanced DR & $0.16(0.01-0.6)^{\star}$ & $0.5(0.1-0.8)^{\star}$ & $0.5(0.1-1.0)^{\star}$ & $0.5(0.1-1.0)^{\star}$ \\
\hline
\end{tabular}

^Significantly different from control group and group with no DR or mild to moderate DR (Kruskal-Wallis ANOVA and multiple comparisons, $\mathrm{p}<0.05$ ).

retinopathy levels were estimated according to the number of microaneurysms and haemorrhages. The number of microaneurysms and haemorrhages in the macular region was rated using a special grid for grading fluorescein angiograms within a radius of $20.0 \mathrm{~mm}$ of the fovea. Microaneurysms were graded from the vascular phase on fluorescein angiograms, and haemorrhages from colour fundus photographs. The number of haemorrhages in the whole retina was also calculated from seven colour fundus photographs and separately, in the upper and lower parts in the temporal and nasal side of the retina. All microaneurysms and haemorrhages were graded on a scale of 0 , no abnormalities, less than 5, from 5-10, and more than 10. Macular oedema or any leakage from retinal vessels was estimated from the late stages of fluorescein angiograms. They were graded as no abnormalities, mild, moderate, or severe. A postoperative incidence of $\mathrm{CMO}$ alone without any other evidence of progression of DR was not considered as a progression of DR.

\section{STATISTICAL METHODS}

Mann-Whitney test and Kruskal-Wallis one way analysis of variance (ANOVA) combined with multiple comparisons $(\mathrm{mc})^{10}$ were used to compare differences in visual acuity between groups. Friedman's two way analysis of variance (ANOVA), combined with comparisons with baseline (cb), was used to evaluate the change of visual acuity after surgery in each diabetic group and controls. ${ }^{10}$ The Fisher exact, two tailed test was used for analysis of data on a nominal scale. $p$ Values less than 0.05 were considered statistically significant.

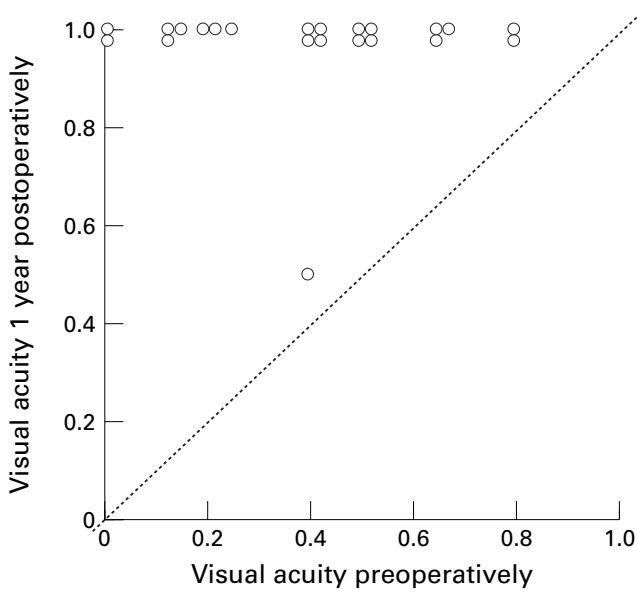

Figure 1 Visual acuity after phacoemulsification in control group 1 year postoperatively.

\section{Results}

VISUAL ACUITY

One year after surgery, visual acuity (VA) with the best spectacle correction was significantly improved compared with preoperative VA in all study groups (Table 2).

\section{Control group}

All non-diabetic control patients had improved visual acuity at 1 year after surgery compared with preoperative VA (Fig 1). One patient from this group had a VA of 0.5 compared with 0.8 at 1 week after surgery because of persistent clinical CMO (Fig 1).

\section{Group with diabetes mellitus}

The visual outcome with the best spectacle correction 1 year after surgery, was improved in 46 eyes $(88 \%)$ of the 52 diabetic eyes (Table $3)$. Only three eyes $(6 \%)$ had a final visual acuity worse than before operation and three eyes (6\%) had the final VA unchanged (Figs 2 and $3)$. Forty one eyes $(79 \%)$ of the 52 diabetic

Table 3 Visual acuity (VA) 1 year after surgery compared with preoperative VA in patients with diabetes mellitus (DM) with different stages of diabetic retinopathy (DR) and controls

\begin{tabular}{|c|c|c|c|}
\hline & \multirow[b]{2}{*}{ No of eyes } & \multicolumn{2}{|c|}{$\begin{array}{l}\text { Visual acuity } 1 \text { year after } \\
\text { surgery }\end{array}$} \\
\hline & & Improved & $\begin{array}{l}\text { Unchanged } \\
\text { or worse }\end{array}$ \\
\hline Control & 22 & 22 & - \\
\hline No DR or mild-mod DR & 27 & 26 & 1 \\
\hline Advanced DR & 25 & 20 & 5 \\
\hline Total with DM & 52 & $46(88 \%)$ & $6(12 \%)$ \\
\hline
\end{tabular}

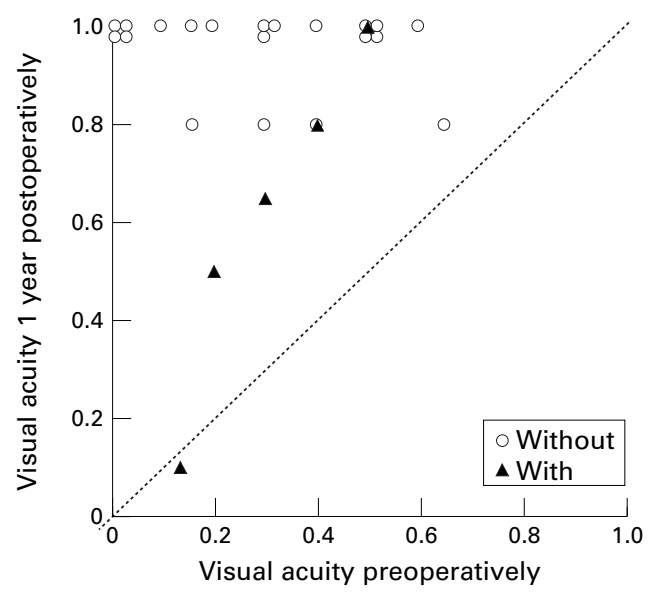

Figure 2 Visual acuity after phacoemulsification in the diabetic group with no DR or mild to moderate $D R$, with and without clinically significant macular oedema 1 year postoperatively. 


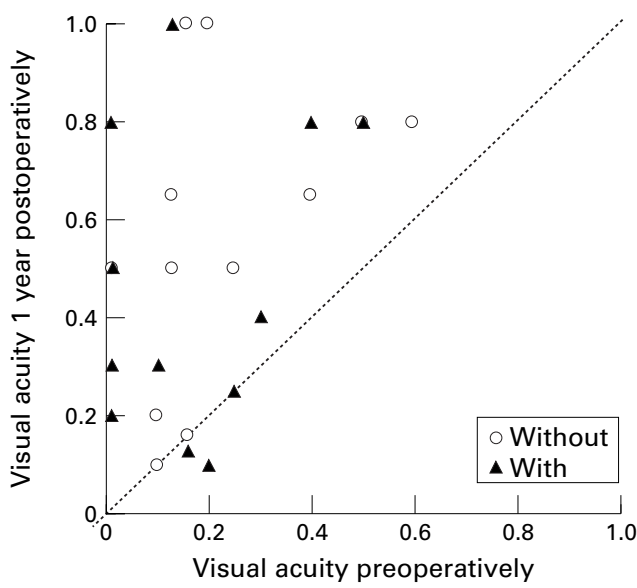

Figure 3 Visual acuity after phacoemulsification in the diabetic group with moderate to severe or proliferative $D R$, with and without clinically significant macular oedema 1 year postoperatively.

eyes achieved a visual acuity 0.5 or better, and 11 eyes $(21 \%)$ had a final VA lower than 0.5 .

Group with no DR or mild to moderate DR

The best corrected visual acuity, 1 year after cataract surgery, in eyes with no DR or mild to moderate DR was not significantly different from that of non-diabetic control patients (Table 2). The visual acuity improved in 26 of 27 eyes to 0.5 or better (median 1.0; range 0.5-1.0) 1 year postoperatively compared with preoperative values (Fig 2). Only one patient had a poor final visual result $(0.1)$ caused by unsuccessfully treated CSMO and persistent cluster of haemorrhages found 1 week postoperatively (Fig 2). An additional comparison showed that five eyes with CSMO 1 week postoperatively had significantly lower visual acuity 3 months and 1 year after surgery compared with 22 eyes without CSMO (Mann-Whitney test, $\mathrm{p}<0.05$ ) (Table 4). Cystoid macular oedema, determined by fluorescein angiography 1 week postoperatively, was found in four eyes with mild to moderate DR, and completely resolved in all, with a good visual acuity $(1.0 ; 0.8-1.0) 1$ year after surgery. Angiographic CMO was associated with CSMO only in one eye with mild to moderate DR.

Group with advanced DR

Eyes with advanced DR had significantly worse visual acuity than eyes in the control group and

Table 4 Visual acuity (VA) up to 1 year after surgery in diabetic patients with no or mild to moderate diabetic retinopathy (DR) and advanced DR, with and without clinically significant macular oedema (CSMO) found 1 week after surgery. All values of VA are given as median (range)

\begin{tabular}{|c|c|c|c|c|c|}
\hline \multirow[b]{3}{*}{ Group } & & \multicolumn{4}{|l|}{ Visual acuity } \\
\hline & & \multirow[b]{2}{*}{ Preoperative } & \multicolumn{3}{|c|}{ Postoperative } \\
\hline & & & 1 week & 3 months & 1 year \\
\hline \multirow[t]{2}{*}{ No DR or mild-moderate DR } & $\begin{array}{l}\mathrm{CSMO}-\mathrm{No} \\
\mathrm{n}=22\end{array}$ & $\begin{array}{l}0.3 \\
(0.01-0.65)\end{array}$ & $\begin{array}{l}1.0 \\
(0.3-1.0)\end{array}$ & $\begin{array}{l}1.0 \\
(0.65-1.0)\end{array}$ & $\begin{array}{l}1.0 \\
(0.1-1.0)\end{array}$ \\
\hline & $\begin{array}{l}\mathrm{CSMO}-\mathrm{Yes} \\
\mathrm{n}=5\end{array}$ & $\begin{array}{l}0.3 \\
(0.13-0.5)\end{array}$ & $\begin{array}{l}0.65 \\
(0.3-1.0)\end{array}$ & $\begin{array}{l}0.8^{\star} \\
(0.3-1.0)\end{array}$ & $\begin{array}{l}0.65^{\star} \\
(0.1-1.0)\end{array}$ \\
\hline \multirow[t]{2}{*}{ Advanced DR } & $\begin{array}{l}\mathrm{CSMO}-\mathrm{No} \\
\mathrm{n}=13\end{array}$ & $\begin{array}{l}0.16 \\
(0.01-0.6)\end{array}$ & $\begin{array}{l}0.65 \\
(0.1-1.0)\end{array}$ & $\begin{array}{l}0.5 \\
(0.1-1.0)\end{array}$ & $\begin{array}{l}0.5 \\
(0.1-1.0)\end{array}$ \\
\hline & $\begin{array}{l}\text { CSMO-Yes } \\
\mathrm{n}=12\end{array}$ & $\begin{array}{l}0.15 \\
(0.01-0.5)\end{array}$ & $\begin{array}{l}0.45 \\
(0.1-0.8)\end{array}$ & $\begin{array}{l}0.4 \\
(0.1-0.8)\end{array}$ & $\begin{array}{l}0.35 \\
(0.1-1.0)\end{array}$ \\
\hline
\end{tabular}

${ }^{\star}$ Significantly different from eyes without CSMO within the same group (Mann-Whitney test, $\mathrm{p}<0.05)$.
Table 5 Progression of diabetic retinopathy (DR) following cataract surgery

\begin{tabular}{|c|c|c|c|c|}
\hline \multirow[b]{2}{*}{ DR 1 week postop } & \multirow{2}{*}{$\begin{array}{l}\text { No of } \\
\text { eyes }\end{array}$} & \multicolumn{3}{|c|}{ Progression of $D R 1$ year after surgery } \\
\hline & & no change & improved & progression \\
\hline No DR & 9 & 9 & - & - \\
\hline Mild-moderate DR & 18 & 6 & 8 & 4 \\
\hline Advanced DR & 25 & 10 & 8 & 7 \\
\hline Total & 52 & 25 & 16 & 11 \\
\hline & $100 \%$ & $48 \%$ & $31 \%$ & $21 \%$ \\
\hline
\end{tabular}

eyes with mild to moderate DR preoperatively and 1 week, 3 months, and 1 year after surgery (Table 2). However, visual acuity was improved in 20 patients $(80 \%)$ (median: 0.57 ; range $0.2-$ $1.0)$, and unchanged or worse in five patients $(20 \%)(0.13 ; 0.1-0.25)$, compared with preoperative values (Fig 3). The cause of poor visual acuity was CSMO found 1 week postoperatively in three eyes. Two eyes did not respond to laser photocoagulation and treatment was delayed in one eye. The fourth patient had optic and retinal atrophy, and the fifth patient suffered a cerebrovascular accident that impaired vision after surgery.

Eyes with CSMO at baseline (1 week postoperatively) had a lower final visual acuity than those without CSMO, but this was not significant (Table 4). Cystoid macular oedema was found on fluorescein angiograms 1 week postoperatively in three eyes with moderate to severe DR and one eye with proliferative DR. In three cases, CMO was associated with CSMO. The final visual acuity of one eye was decreased to 0.1 . In one eye with proliferative stage and CSMO, it was difficult to estimate the existence of CMO from angiography performed 1 week after surgery. Neodymium YAG (Nd:YAG) laser posterior capsulotomy was performed in one patient with proliferative DR at 8 months after surgery.

PROGRESSION OF DIABETIC RETINOPATHY

Table 5 summarises the progression of diabetic retinopathy. Following cataract surgery, DR showed no change or improved in 41 eyes $(79 \%)$, and progressed in 11 eyes $(21 \%)$ (Table $5)$. No eye without retinopathy progressed to non-proliferative or proliferative DR. Progression was found in 11 eyes $(25.6 \%)$ with DR, in four eyes with mild to moderate $\mathrm{DR}$, in six eyes with moderate to severe $\mathrm{DR}$, and in one eye with proliferative DR. Two eyes, one eye with mild to moderate DR and a second eye with moderate to severe DR, progressed to proliferative DR. The second eye also developed vitreous haemorrhage, which resolved after laser photocoagulation. Progression appeared in five eyes during 3 months postoperatively and in six eyes from 3 months until 1 year after surgery. New postoperative cases of CSMO were found 1 year postoperatively in two eyes, in one with mild to moderate DR and in a second with moderate to severe DR.

Cystoid macula oedema was found in eight diabetic eyes (8/51; about $15 \%$ ) based on fluorescein angiograms only at 1 week postoperatively. Cystoid macular oedema was associated with CSMO in one eye with mild to moderate DR and in three eyes with moderate to severe 
Table 6 Clinical characteristics of diabetic patients with and without progression of retinopathy after phacoemulsification during 1 year follow up study

\begin{tabular}{llll}
\hline & No progression & Progression & $\begin{array}{c}\text { Differences } \\
\text { between groups }\end{array}$ \\
\hline No of eyes (\%) & $41(79 \%)$ & $11(21 \%)$ & \\
Age (years) & $73(53-86)$ & $75(49-83)$ & \\
Male/female & $17 / 24$ & $3 / 8$ & \\
Type 1/type 2 & $5 / 36$ & $1 / 10$ & \\
Insulin treatment & 29 & 8 & \\
Duration of diabetes (years) $\dagger$ & $19(5-55)$ & $14(8-31)$ & \\
Final visual acuity† & $0.8(0.1-1.0)$ & $0.65(0.1-1.0)$ & \\
CSMO at baseline & 12 & 5 & $\mathrm{p}<0.05^{\star}$ \\
Postop CSMO, new cases & - & 2 & $\mathrm{p}<0.05^{\star}$ \\
Angiographic CMO at baseline & 6 & 2 & \\
Indication for laser treatment at baseline & 21 & 10 & \\
\hline
\end{tabular}

$\mathrm{CSMO}=$ clinically significant macular oedema $\mathrm{CMO}=$ cystoid macular oedema; baseline $=1$ week after surgery.

†Values are given as median (range); *significant difference between groups (Fisher exact test, $\mathrm{p}<0.05)$.

DR. No cystoid macular oedema was recorded in eyes without DR. Two eyes with angiographic CMO, one with mild to moderate DR, and another with moderate to severe DR, had a progression of DR. However, eyes with angiographic CMO or CSMO were not at a significantly higher risk for progression of DR (Table 6 ). Eyes with an indication for laser photocoagulation at baseline had significantly higher rate of progression of DR than eyes with no indication (Table 6).

\section{Discussion}

In the present study the visual acuity after phacoemulsification was improved in a majority of the operated eyes ( $88 \%$ ), and $79 \%$ of eyes had a visual acuity of 0.5 or better 1 year postoperatively. Our results are similar to those reported by Antcliff et al. ${ }^{11}$ According to the report by Henricson et $a l,{ }^{12} 89 \%$ of diabetic eyes achieved the similar result 2 years after cataract surgery where both ECCE and phacoemulsification procedures were used. We also evaluated retinopathy 1 year after surgery, and $21 \%$ of diabetic eyes showed a progression in DR, similar to a previous report where retinopathy deteriorated in $23.4 \%$ of eyes 1 year after phacoemulsification. ${ }^{13}$

It is known that diabetic eyes have more complications after cataract surgery than nondiabetic eyes, particularly more pronounced postoperative inflammation ${ }^{14-16}$ and a poorer visual acuity. ${ }^{17} 18$ Many authors have tried to identify risk factors for visual prognosis and progression of DR following cataract surgery in diabetic eyes. Diabetic eyes have many disturbances within the anterior segment, such as a bigger lens, ${ }^{19}$ a steeper anterior lens curvature, and a shallower anterior chamber, especially in eyes with diabetic retinopathy. ${ }^{2021}$ These changes may make surgery more difficult. The diabetic eye is also more susceptible to surgical trauma than the non-diabetic eye. Surgically more pronounced miosis, ${ }^{22}$ a longer duration of surgery, ${ }^{22}$ a more fragile lens capsule with a higher rate of rupture, ${ }^{23}$ a higher postoperative flare intensity, ${ }^{16}$ a transient elevation of intraocular pressure, ${ }^{1124}$ and a higher incidence of angiographic cystoid macular oedema ${ }^{25}$ have been found in diabetic eyes.

Surgical technique contributes to the incidence of postoperative complications in the anterior and the posterior segment of the eye.
The breakdown of blood-aqueous barrier (BAB) by surgical trauma produces postoperative inflammation ${ }^{26}$ with a pigment dispersion, a fibrinoid reaction, and development of posterior synechiae. ${ }^{14} 1527$ The advantage of phacoemulsification is that this technique with a small incision reduces the postoperative breakdown of BAB. ${ }^{4}$ Therefore, significantly less fibrinoid reaction is found in the anterior chamber of diabetic eye during first postoperative week after phacoemulsification, compared with ECCE. ${ }^{27}$

The surgical procedure also may contribute to the progression of diabetic retinopathy, ${ }^{2427} 28$ and deterioration of pre-existing diabetic maculopathy. ${ }^{18} \mathrm{CMO}$ occurs more frequently in eyes with diabetes than in non-diabetics, ${ }^{24}{ }^{25}$ and more often in eyes with retinopathy than without retinopathy. ${ }^{25}{ }^{29}$ In other studies, the incidence of angiographic CMO found after ECCE varied from $39 \%$ to $50 \%$, with and without DR. ${ }^{18}{ }^{30}$ In contrast, in our study angiographic CMO was found in only $15 \%$ of all diabetic eyes. In addition, angiographic CMO was not recorded in eyes with no DR and was not more pronounced in eyes with CSMO. The possible explanation for these results is that a phacoemulsification technique with a small incision was used. ${ }^{4}$ In addition, an HSM PMMA IOL was implanted in the capsular bag, and these lenses may reduce postoperative inflammation. ${ }^{56}$

The degree of postoperative inflammation in diabetic eyes after phacoemulsification is related principally to the preoperative $\mathrm{DR}$, which depends mostly on the course of DM. ${ }^{16}$ The highest postoperative flare values were found in diabetic eyes with advanced stages of DR and those with CSMO. ${ }^{16}$ These results indicate that the activity and severity of pre-existing retinopathy seem to be one of the major risk factors for postoperative complications. Some previous clinical studies showed that patients with maculopathy at the time of surgery had the worst postoperative prognosis relative to visual acuity after ECCE EC $^{1731}$ or phacoemulsification. ${ }^{11}$ In the present study, we also found that the postoperative visual acuity reflects the status of the macula at 1 week postoperatively. However, eyes with CSMO and angiographic CMO had a similar rate of progression of retinopathy to eyes without maculopathy. In our study, eyes that progressed, had active retinopathy 1 week postoperatively, particularly those with moderate to severe DR and mild to moderate DR. According to our results and other studies, we believe that VA after cataract surgery depends on the severity of diabetic retinopathy at the time of surgery. ${ }^{29} 3233$

We conclude that the final visual outcome was improved in the majority of diabetic eyes. Eyes with CSMO at the time of surgery had the worst prognosis regarding postoperative visual acuity. The activity of diabetic retinopathy at the time of surgery appears to be a major factor causing the progression of retinopathy after cataract surgery. 
1 Kleinbek R, Moss SE. Prevalence of cataracts in a population-based study of persons with diabetes mellitus. Pphthather 1985:92:1191-6.

2 Nielsen NV, Vinding T. The prevalence of cataract in insulin-dependent and non-insulin-dependent-diabetes mellitus. Acta Ophthalmol Scand 1984;62:595-602.

3 Zheng L, Merriam JC, Zaider M. Astigmatism and visual recovery after "large incision" extracapsular cataract surgery and "small" incisions for phacoemulsification. Trans Am Ophthalmol Soc 1997;95:387-410; discussion $410-5$. 4 Laurell CG, Wickstrom K, Zetterstrom C, et al. Inflamma-
tory response after endocapsular phacoemulsification or conventional extracapsular lens extraction in the rabbit eye. Acta Ophthalmol Scand 1997;75:401-4.

5 Percival P. Use of heparin-modified lenses in high-risk cases for uveitis. Dev Ophthalmol 1991;22:80-3.

6 Zetterström C, Lundvall A, Olivestedt G. Exfoliation syndrome and heparin surface modified intraocular lenses. Acta Ophthalmol Scand 1992;70:91-5.

7 Early Treatment Diabetic Retinopathy Study Research Group. Photocoagulation for diabetic macular edema:
Early treatment Diabetic Retinopathy Study report Early treatment Diabetic Retinopathy Stud

8 Klein R, Klein BE, Moss SE, et al. The Wisconsin Epidemiologic Study of Diabetic Retinopathy. IX. Fouryear incidence and progression of diabetic retinopathy when age at diagnosis is less than 30 years. Arch Ophthalmol 1989;107:237-43.

9 Gass JD, Norton EW. Cystoid macular edema and papilledema following cataract extraction. A fluorescein fundoscopic and angiographic study. Arch Ophthalmol 1966;76:646-61.

10 Siegel S, Castellan NJ. Nonparametric statistics for the behavioural sciences. Singapore: McGraw-Hill International Editions, 1988, Chapter 7-8.

11 Antcliff RJ, Poulson A, Flanagan DW. Phacoemulsification in diabetics. Eye 1996;10:737-41.

12 Henricsson M, Heijl A, Janzon L. Diabetic retinopathy before and after cataract surgery. Br f Ophthalmol 1996;80: 789-93.

13 Wagner T, Knaflic D, Rauber M, et al. Influence of cataract surgery on the diabetic eye: a prospective study. Ger $\mathcal{F} O p h-$ thalmol 1996;5:79-83.

14 Cunliffe IA, Flanagan DW, George ND, et al. Extracapsular cataract surgery with lens implantation in diabetics with and without proliferative retinopathy. $\mathrm{Br} \mathcal{F}$ Ophthalmol 1991;75:9-12.

15 Krupsky S, Zalish M, Oliver M, et al. Anterior segment complications in diabetic patients following extracapsular cataract extraction and posterior chamber intraocular lens implantation. Ophthalmic Surg 1991;22:526-30.

16 Zaczek A, Zetterström C. Aqueous flare intensity after phacoemulsification in patients with diabetes mellitus. $\mathcal{F}$ Cataract Refract Surg 1998;24:1099-104.

17 Benson WE, Brown GC, Tasman W, et al. Extracapsular cataract extraction with placement of a posterior chamber cataract extraction with placement of a posterior chamber
lens in patients with diabetic retinopathy. Ophthalmology 1993;100:730-8.
18 Pollack A, Leiba $\mathrm{H}$, Bukelman A, et al. The course of diabetic retinopathy following cataract surgery in eyes previously treated by laser photocoagulation. $\mathrm{Br} \mathcal{F}$ Ophthalmol 1992,76:228-31.

19 Brown N, Hungerford J. The influence of the size of the lens in ocular disease. Trans Ophthalmol Soc UK 1982;102:35963.

20 Sparrow JM, Bron AJ, Phelps Brown NA, et al. Biometry of the crystalline lens in late onset diabetes: the importance of diabetic type. Br $\mathcal{F}$ Ophthalmol 1992;76:428-33.

21 Sparrow JM, Bron AJ, Brown NA, et al. Autofluorescence of the crystalline lens in early and late onset diabetes. $\mathrm{Br} F$ Ophthalmol 1992;76:25-31.

22 Zaczek A, Zetterström C. Cataract surgery and pupil size in patients with diabetes mellitus. Acta Ophthalmol Scand 1997;75:429-32.

23 Kuchle M, Schonherr U, Dieckmann U. (Risk factors for capsular rupture and vitreous loss in extracapsular cataract extraction. The Erlangen Ophthalmology Group.) Fortschr Ophthalmol 1989;86:417-21.

24 Kodama T, Hayasaka S, Setogawa T. Plasma glucose levels, postoperative complications, and progression of retinopathy in diabetic patients undergoing intraocular lens implantation. Graefes Arch Clin Exp Ophthalmol 1993;231: 439-43.

25 Menchini U, Bandello F, Brancato R, et al. Cystoid macular oedema after extracapsular cataract extraction and intraocular lens implantation in diabetc patients without retinopathy. Br f Ophthalmol 1993;77:208-11.

26 Miyake K, Sugiyama S, Norimatsu I, et al. Prevention of cystoid macular edema after lens extraction by topical indomethacin (III) radioimmunoassay measurement of prostaglandins in the aqueous during and after lens extraction procedures. Graefes Arch Clin Exp Ophthalmol 1987; 209:83-8.

27 Muller-Jensen K, Rorig M, Hagele J, et al. (Effect of cataract technique and duration of surgery on fibrin reaction after IOL implantation.) (French) Ophtalmologe 1997;94:38-40.

28 Levin ML, Kincaid MC, Eifler CW, et al. Effect of cataract surgery and intraocular lenses on diabetic retinopathy. $\mathcal{F}$ Cataract Refract Surg 1985;14:642-9.

29 Cheng H, Franklin SL. Treatment of cataract in diabetics with and without retinopathy. Eye 1988;2:607-14.

30 Pollack A, Leiba H, Bukelman A, et al. Cystoid macular oedema following cataract extraction in patients with diabetes. Br f Ophthalmol 1992;76:221-4.

31 Pollack A, Dotan S, Oliver M. Progression of diabetic retinopathy after cataract extraction. Br f Ophthalmol 1991;75: 47-51.

32 Dowler JG, Hykin PG, Lightman SL, et al. Visual acuity following extracapsular catract extraction in diabetes: a metaanalysis. Eye 1995;9:313-7.

33 Hykin PG, Gregson RM, Hamilton AM. Extracapsular cataract extraction in diabetics with rubeosis iridis. Eye 1992;6:296-9. 